\title{
Absolute mRNA levels and transcriptional regulation of the mouse testis-specific thioredoxins
}

\author{
Alberto Jiménez ${ }^{\mathrm{a}, \mathrm{b}, \mathrm{e}}$, María J. Prieto-Álamo ${ }^{\mathrm{c}, \mathrm{e}}$, Carlos A. Fuentes-Almagro ${ }^{\mathrm{c}}$, Juan \\ Jurado $^{\mathrm{c}}$, Jan-Åke Gustafsson ${ }^{\mathrm{a}}$, Carmen Pueyo ${ }^{\mathrm{c}}$ and Antonio Miranda-Vizuete ${ }^{\mathrm{a}, \mathrm{d}, *}$
}

${ }^{\mathrm{a}}$ Center for Biotechnology, Department of Biosciences at NOVUM, Karolinska Institutet, S14157 Huddinge, Sweden.

${ }^{\mathrm{b}}$ Departamento de Microbiología y Genética, Universidad de Salamanca, Edificio Departmental, lab. 323, 37007 Salamanca, Spain.

${ }^{c}$ Departamento de Bioquímica y Biología Molecular, Campus de Rabanales, Edificio Severo Ochoa, Planta 2a . Carretera Madrid-Cádiz Km 396-a. Universidad de Córdoba. 14071 Córdoba. Spain.

${ }^{\mathrm{d} C e n t r o}$ Andaluz de Biología del Desarrollo (CABD-CSIC), Departamento de Ciencias Ambientales, Universidad Pablo de Olavide, 41013 Sevilla, Spain.

${ }^{\mathrm{e}}$ These authors contributed equally to this work.

*To whom correspondence should be addressed: $\quad \underline{\text { amirviz@upo.es }}$

Phone: +34954349381

Fax: $\quad+34954349376$ 


\section{ABSTRACT}

Thioredoxins function as general protein disulphide reductases. Mammalian male germ cells are equipped with a set of three testis-specific thioredoxins named Sptrx-1, -2 and -3 , respectively. Sptrx proteins are expressed either in different structures within the sperm cell or at different stages of sperm development, suggesting a refined regulation in the timing and levels of expression for each Sptrx gene. Previous studies based on qualitative northern-blot and in situ hybridization analyses restricted the presence of Sptrx mRNAs to adult testis, but nothing is known about their transcriptional regulation or relative expression levels in this tissue.

In this report we investigate the transcriptional profiles of the mouse Sptrx genes in terms of the germ cell-specific regulation by promoter analysis in GC-2spd(ts) cells. Besides, we perform a comprehensive quantification of the Sptrx mRNA molecules by real-time PCR in wholeanimal experiments. By these means, we show that transcription is differentially regulated for each Sptrx gene and identify the 5'-flanking regions anticipated to contain the cis-regulatory elements responsible, at least in part, for the transcriptional silencing and/or activation of the Sptrx genes. In addition we show remarkable age-associated variations between the Sptrx mRNA expression patterns. Finally we corroborate the testis-specific expression pattern of Sptrx-2 and Sptrx-3, but surprisingly we find a wider expression pattern for Sptrx-1

Keywords: Thioredoxin, sperm, testis, promoter, gene expression, real-time PCR 


\section{INTRODUCTION}

Cellular redox balance is maintained in living organisms by various non-enzymatic as well as enzyme-based systems [1]. Among them, thioredoxin (Trx) and related proteins have emerged as one of the most important thiol-based systems being involved in many physiological as well as pathophysiological processes [2]. The mammalian thioredoxin system consists of the hydrogen donor NADPH and the selenoprotein thioredoxin reductase (TrxR) coupled to the redox active protein thioredoxin $[3,4]$. Eukaryotic organisms are equipped with two ubiquitous thioredoxin systems: a cytoplasmic one composed of Trx-1 and TrxR-1, and a mitochondrial one formed by Trx-2 and TrxR-2 [3,5]. Moreover, different forms of thioredoxins and thioredoxin reductases with unique properties such as organelle- or tissue-specific localization have been reported [6-11]. In this regard, male germ cells are endowed with three testis-specific thioredoxins named Sptrx-1 [12, 13], Sptrx-2 [14, 15] and Sptrx-3 [16], respectively, thus reflecting a key role of this family of proteins in spermatogenesis.

Sptrx-1 comprises one N-terminal repetitive domain of a 15 amino acid motif and one Cterminal thioredoxin domain [12, 13] displaying both reducing and oxidizing activities [17]. Sptrx-1 is located in the developing tail of elongating spermatids, transiently associated with the longitudinal columns of the fibrous sheath. This transient association during sperm tail formation strongly supports a regulatory role of Sptrx-1 in sperm development $[12,13]$. Sptrx-2 is also a multi-domain protein composed by one N-terminal thioredoxin domain followed by three NDP-kinase domains $[14,15]$. Sptrx-2 is associated with the longitudinal columns of the sperm fibrous sheath and also with the ribs that connect these two columns. Unlike Sptrx-1, Sptrx-2 becomes a structural part of the mature sperm tail and can be detected in ejaculated spermatozoa. Sptrx-2 could be involved in the reduction of disulfide bonds within the sperm fibrous sheath components $[14,15]$. In contrast to Sptrx-1 and Sptrx-2, the Sptrx-3 gene codes for a unique thioredoxin domain and was originated as a genomic duplication of the $\operatorname{Tr} x-1$ gene [16]. Sptrx-3 is a Golgi apparatus-associated thioredoxin showing a transient association with the developing spermatid acrosome. Its function might be related to the post-translational modification of proteins required for acrosomal biogenesis [16].

Spermatogenesis is a complex process leading to the formation of one haploid motile cell and the specific gene expression occurring through spermatogenesis must be tightly regulated and coordinated $[18,19]$. Transcription initiation is a key regulatory step in the modulation of gene expression and involves the interaction of many transcription factors and cis-regulatory DNA elements [20]. During spermatogenesis, spermatogenic cell-specific genes are expressed as well 
as spermatogenic cell-altered transcripts due to different transcription start sites usage, alternative polyadenylation or splicing and mRNA shortening or degradation [21]. As mentioned above, a rigorous regulation in the timing and levels of gene expression is required and likewise transcriptional initiation regulatory mechanisms, post-transcriptional regulatory pathways are crucial for spermatogenesis [22]. For example, transcriptional machinery is inactive in elongating spermatids due to the changes occurring in the chromatin structure and nuclear elongation; in contrast, pachytene spermatocytes and round spermatids are transcriptionally active and display very similar transcription rates [21]. Thus, some mRNAs are transcribed during pachytene spermatocyte or round spermatid stages and then stored as transcriptionally repressed free messenger ribonucleoprotein particles to be actively translated in elongated spermatids [21].

Here we report the first analysis of the mouse Sptrx-1, Sptrx-2 and Sptrx-3 gene transcription by characterizing their corresponding promoters and also by performing a meticulous quantification of their steady-state mRNA copy numbers. 


\section{MATERIALS AND METHODS}

\subsection{Luciferase reporter constructs}

BAC clones RP23-291E22, RP23-332H6 and RP23-332H16 containing mouse Sptrx-1, Sptrx-2 and Sptrx-3 genomic regions respectively were obtained from BACPAC Resources Center (http://bacpac.chori.org/). All the Sptrx 5'-flanking regions were amplified by PCR using combinations of the mutagenic primers listed in Supplemental Data Table 1, which introduced unique restriction sites (MluI/XhoI for Sptrx-1 and Sptrx-3 and MluI/BglII for Sptrx-2) at the 5' and 3' ends, respectively. All the PCR products were first cloned into pGEM-Teasy (Promega) and subsequently verified by sequencing and comparison with sequences deposited at NCBI (http://www.ncbi.nlm.nih.gov/genome//guide/mouse/). Next, the Sptrx 5'-flanking regions were removed from the pGEM-Teasy constructs by restriction enzyme digestion and cloned into the promoterless firefly luciferase reporter vector pGL-3 basic (Promega).

\subsection{Cell Culture, transfections and luciferase assay}

GC-2spd(ts) (ATCC no. CRL-2196), Hepa1-6 (ATCC no. CRL-1830) and Y-1 (ATCC no. CCL-79) cell lines were obtained from the American Type Culture Collection. All media and supplements were purchased from Life Technologies. Cells were grown in Dulbecco's Modified Eagle's Medium (DMEM) at $37^{\circ} \mathrm{C}$ or $32^{\circ} \mathrm{C}$ in an atmosphere of $5 \% \mathrm{CO}_{2}$. GC-2spd(ts) cells were supplemented with $1 \mathrm{mM}$ non-essential amino-acids. All media contained 10\% fetal bovine serum (FBS) and 2mM L-glutamine.

Transient transfections were performed in 24-well plates using Lipofectamine ${ }^{\mathrm{TM}} 2000$ (Life Technologies) according to the manufacturer's instructions. A total of $0.5 \mu \mathrm{g}$ to $1 \mu \mathrm{g}$ of DNA was used in each reaction. Cells were incubated for 48 hours before lysis and preparation of cellular extracts. Independent parallel transfections using exclusively the pEGFP-N3 vector (Clontech) were always included as additional control for transfection efficiency, measured as number of cells expressing GFP.

Enzyme activity assays were performed to measure luciferase expression levels (Luciferase Assay Kit, Biothema AB, Sweden) using a Berthold FB12 luminometer (Berthold detection systems, Germany). 


\subsection{Animals}

Male BALB/c mice of 7 weeks of age were purchased from Charles River Laboratories (Spain). Mice of other ages were obtained through the "Servicio de Animales de Experimentación of Córdoba University”. Animals were individually killed by cervical dislocation. Testes were then removed and immediately frozen in liquid nitrogen. Mice were handled according to the policies and procedures stipulated by the European Community. The investigation was approved by the Ethical Committee of Córdoba University.

\subsection{RNA Preparations and Reverse Transcription}

RNA extraction and synthesis of standard RNA and cDNA were performed as described [23]. Commercial RNAs were purchased from Clontech, except for ovary total RNA that was obtained from Ambion. RNA sample quality was checked electrophoretically and quantification was performed spectrophotometrically. Lack of genomic DNA contamination was confirmed by PCR amplification of RNA samples without previous cDNA synthesis.

\subsection{Primer design for real-time PCR}

Primers were designed in silico using Oligo 6.1.1/98 software (Molecular Biology Insights). To obtain the highest specificity and performance, primers were required to have high $\operatorname{Tm}(\geq$ $\left.80^{\circ} \mathrm{C}\right)$ and optimal $3^{\prime} \Delta \mathrm{G}(\geq-6.7 \mathrm{kcal} / \mathrm{mol})$ values. Several pairs of primers were designed for each Sptrx gene (Table 2). All primer pairs generated specific PCR products of the desired length. PCR products were further verified by nucleotide sequencing.

\subsection{Real-time PCR}

Real-time PCR conditions were as detailed [23]. PCR reactions were performed in quadruplicate. No primer-dimers were detected, and investigated transcripts showed optimal PCR efficiencies. An absolute standard curve was constructed with an external standard in the range of $10^{2}$ to $10^{9}$ RNA molecules. The number of mRNA molecules was calculated from the linear regression of the standard curve, as previously described [23]. 


\section{RESULTS}

\subsection{Sptrx mRNA and protein expression levels in GC-spd(ts) cell line}

Promoter analysis studies offer valuable information about transcriptional regulation during spermatogenesis. The identification of the cis-acting and trans-acting elements directing the spermatogenic-specific transcription of Sptrx genes is essential to shed more light onto their role in sperm physiology. However, a major limitation to this approach is the availability of adequate cell lines that can recapitulate different aspects of spermatogenesis. To our knowledge, GC$\operatorname{spd}(\mathrm{ts})$ is the only spermatogenic mouse cell line available, which is able to undergo meiosis in vitro and develop a primordial tail and acrosome when cultured at $32^{\circ} \mathrm{C}$ [24]. To test whether the Sptrx genes are expressed in GC-2spd(ts) cells, we performed western-blot analysis on crude protein extracts from these cells grown at $37^{\circ} \mathrm{C}$ and $32^{\circ} \mathrm{C}$, but we were unable to detect any of the three proteins (data not shown). As this result may only reflect the translational inactivity of the Sptrx transcripts, we followed to measure the actual numbers of Sptrx mRNA molecules in GC-2spd(ts) cells. In agreement with their protein levels, the Sptrx-2 and Sptrx-3 mRNAs were virtually absent $(\leq 0.001$ molecules/pg total RNA); however, although at very low levels, we succeeded to detect and quantify the Sptrx- 1 transcript at both $37^{\circ} \mathrm{C}(0.083$ molecules/pg $)$ and $32^{\circ} \mathrm{C}(0.457$ molecules/pg).

Overall, these data indicate that the GC-spd(ts) cell line has very low or undetectable Sptrx mRNA and protein levels suggesting that their expression is repressed or silenced.

\subsection{Promoter activity of the 5'-flanking region of the Sptrx genes}

Genomic sequences corresponding to the 5'-flanking regions of mouse Sptrx-1, Sptrx-2 and Sptrx-3 genes were identified and cloned into the promoterless pGL-3 basic vector (Fig. 1). These 5'-flanking regions ranged from -1 to $-4 \mathrm{~kb}$ upstream the initiation codon of each Sptrx gene. Reverse orientations of the $-4 \mathrm{~kb}$ fragments were also included as negative controls. Next, the ability of each fragment to promote transcription was evaluated by means of a luciferase reporter gene assay in GC-2spd(ts) cells. The experiments were initially carried out at both $37^{\circ} \mathrm{C}$ and $32^{\circ} \mathrm{C}$. However, as no difference was found in the promoter activity (data not shown), we decided to perform additional experiments only at $37^{\circ} \mathrm{C}$.

The results presented in Fig. 2 indicate considerable differences among the promoter activities of the 5'-flanking regions of the three Sptrx genes. Thus, while the Sptrx-1-1kb region did not display any promoter activity compared with the empty vector, the promoter activities of the Sptrx-2 and Sptrx-3-1kb regions were significantly higher than the control, being maximal in the case of Sptrx-2. Further differences appeared when we expanded the analysis to $-2 \mathrm{~kb}$ 
regions. Hence, the Sptrx-1 $-2 \mathrm{~kb}$ fragment resulted in maximal promoter activity while, conversely, the Sptrx $-2-2 \mathrm{~kb}$ fragment significantly reduced that obtained with its corresponding $-1 \mathrm{~kb}$ region. In contrast, the Sptrx-3 $-2 \mathrm{~kb}$ region did not display any statistically significant change of the promoter activity obtained with the $-1 \mathrm{~kb}$ alone. Noteworthy, the $-4 \mathrm{~kb}$ region of Sptrx-3 displayed the maximal promoter activity, while the equivalent region of both Sptrx-1 and Sptrx-2 5'-flanking regions showed no significant luciferase activity compared with the empty vector.

In addition to GC-2spd(ts), we transfected two other non-related mouse cell lines, Hepa1-6 (hepatoma) and Y-1 (adrenal gland). In these two non-spermatogenic mouse cell lines, the luciferase activities of the Sptx-1, Sptrx-2 and Sptrx-3 constructs were essentially the same as in the GC-2spd(ts) cells (Supplemental Data Fig. 1). Only the Sptrx-3 -4kb construct revealed a significant difference showing as low promoter activity as those of the $-2 \mathrm{~kb}$ and $-1 \mathrm{~kb}$ regions in these two cell lines (Supplemental Data Fig. 1). Collectively, the results obtained in Hepa1-6 and Y-1 cells are mostly consistent with the Sptrx null expression profiles observed in GC$2 \operatorname{spd}(\mathrm{ts})$ since we did not find any clear differences among the three cell lines. On the other hand, the $-2 \mathrm{~kb}$ distal regions (between $-2 \mathrm{~kb}$ and $-4 \mathrm{~kb}$ ) of both Sptrx-1 and Sptrx-2 5'-flanking regions seem to account for a transcriptional silencing of these genes in the cell lines used in the study. The situation is reversed for the Sptrx-3 promoter in GC-2spd(ts) cells, as the distal sequence present in the $-4 \mathrm{~kb}$ construct resulted in the highest promoter activity.

To gain more insight into the molecular mechanisms influencing the Sptrx transcriptional activities, we decided to analyze more in detail the distal 5'-flanking regions of Sptrx-1, Sptrx-2 and Sptrx-3 genes. Therefore, we made new constructs with the $2 \mathrm{~kb}$ distal regions (from $-2 \mathrm{~kb}$ to $-4 \mathrm{~kb}$ from ATG) of Sptrx-1 and Sptrx-2 (Fig. 1) to investigate their ability to abolish any transcriptional activity. Also, we included as additional negative control the reverse orientations of those sequences that rendered the highest activity in the previous experiments $(-2 \mathrm{~kb}$ reverse for Sptrx-1 and $-1 \mathrm{~kb}$ reverse for Sptrx-2, Fig. 2). Finally, we designed a new $-3 \mathrm{~kb}$ construct for Sptrx-3 (Fig. 1) to check whether promoter activity of its 5'-flanking region increases with sequences longer than $-2 \mathrm{~kb}$. To shorten the analysis we restricted the study to GC-2spd(ts) cell line due to the lack of clear differences with Hepa1-6 and Y-1 cell lines in the luciferase assays.

As shown in Fig. 2, Sptrx-1 and Sptrx-2 -2kb distal regions exhibited null promoter activity, being even lower than that of the empty pGL-3 basic vector. Interestingly, while the reverse orientation of the $-2 \mathrm{~kb}$ and $-4 \mathrm{~kb}$ regions of Sptrx-1 showed no activity as expected, the reverse $-1 \mathrm{~kb}$ and $-4 \mathrm{~kb}$ regions of Sptrx-2 displayed significant promoter activities (Fig. 2). Surprisingly, the $-3 \mathrm{~kb}$ region of Sptrx-3 did not show any promoter activity (Fig. 2) suggesting the presence of a silencing regulatory element in the $-2 \mathrm{~kb}$ to $-3 \mathrm{~kb}$ fragment. 
Taken together, these results indicate the existence of different mechanisms of transcriptional regulation for each Sptrx gene. First, the $-2 \mathrm{~kb}$ distal region of Sptrx-1 appears to be responsible for a strict transcriptional repression; however the lack of promoter activity within the $-1 \mathrm{~kb}$ region may imply other regulatory mechanisms in the proximal $-2 \mathrm{~kb}$ region, which may be considered to contain the core promoter for Sptrx-1 (Fig. 2). Second, the $-1 \mathrm{~kb}$ fragment of Sptrx-2 displayed the maximal promoter activity and therefore we propose this region to be the core promoter for Sptrx-2; furthermore, although the $-2 \mathrm{~kb}$ distal region seems to play a role in the transcriptional repression, we cannot exclude other regions between $-1 \mathrm{~kb}$ to $-2 \mathrm{~kb}$ participating in this negative regulation (Fig. 2). Third, since all the Sptrx-3 5'-flanking regions displayed significant promoter activity except for the $-3 \mathrm{~kb}$ construct, it is plausible to consider the core promoter for Sptrx-3 to be located in the $-1 \mathrm{~kb}$ fragment; the existence of potential cisregulatory elements in the $-2 \mathrm{~kb}$ to $-3 \mathrm{~kb}$ interval as well as distal enhancer sequences in the $-3 \mathrm{~kb}$ to $-4 \mathrm{~kb}$ interval are also suggest by our results (Fig. 2).

\subsection{Sequence analysis of the 5'-flanking region of the Sptrx genes}

The 5'-flanking regions of the Sptrx genes were used to localize putative promoter sequences, cis-regulatory modules and other significant elements using the Eldorado program included in the GenomatixSuite 3.1.1 software (http://www.genomatix.de/). The output forms from this analysis are summarized in Fig. 3. Core promoters are predicted to be localized within regions of about $600 \mathrm{bp}$ in the first $1.5 \mathrm{~kb}$ from ATG where different regulatory modules are located: EGRF/NFAT (-1091 to -1113) and glucocorticoid responsive element/Nuclear Factor 1 (-767 to -804) in the Sptrx-1 promoter; interferon regulatory factor/ETS1 (-655 to -678) in the Sptrx-2 promoter and BRAC/HOX (-407 to -437), HOX/mouse Krueppel-like factor (-404 to -429) and enhancer CCAAT binding factor/SREBP1 (-229 to -259) in the Sptrx-3 promoter. Furthermore, two repetitive regions were found: one of 1206 bp in the Sptrx-2 5'-flanking region and another one of 4394 bp in the Sptrx-3 5'-flanking region.

In addition, we used the MatInspector program included in GenomatixSuite 3.1.1 software (http://www.genomatix.de/) to look for putative transcription factor binding sites in the $-1 \mathrm{~kb}$ region from the ATG of each Sptrx 5'-flanking region. The most significant binding sites are listed in Table 1 and it is noteworthy that the analysis did not retrieve any TATA-box within the $-1 \mathrm{~kb}$ region of Sptrx-1. The fact that Sptrx-1 $-1 \mathrm{~kb}$ construct does not show any promoter activity (Fig. 1) may be related to the lack of any TATA-box within this region or the presence of the EGRF/NFAT regulatory module outside the $-1 \mathrm{~kb}$ region. 


\subsection{Testicular Sptrx mRNA molecule numbers}

Initial studies on mouse Sptrx mRNA expression patterns were based on qualitative multipletissue northern blots and in situ hybridization analyses [13, 15, 16]. Here, we used a quantitatively rigorous approach based on reverse transcription followed by real-time PCR amplification [23] to provide for the first time a valuable new information on the steady-state copy numbers of the three murine Sptrx-1, Sprtx-2 and Sptrx-3 transcripts.

We first wanted to know how the mouse male fine-tunes the number of testicular mRNA molecules during aging. Therefore, two primer pairs were initially designed per each Sptrx gene. These primers amplify a proximal or distal sequence away from the corresponding $5^{\prime}$-UTR (Table 2). For comparison, transcript levels for the novel form of thioredoxin/glutathione reductase (TGR) and for the cytosolic thioredoxin system (Trx1 and TrxR1) were quantified in parallel.

As shown in Table 3, vast differences in transcript abundance depending on the primer pair were found for two (Sptrx-1 and Sptrx-3) out of the three investigated Sptrx genes. Remarkably, in 7-week-old animals, SPT1.5 that amplifies part of the sequence encoding the C-terminal thioredoxin domain, quantified only $9.4 \%$ (82 vs 876 molecules/pg) of the Sptrx-1 mRNA molecules given by SPT1.2, which amplifies the fragment containing the proposed start codon [13]. Regarding the primer pair used for quantification of Sptrx-3 mRNA, SPT3.6 located in exons 5 and 6 quantified only $4.2 \%$ (4.7 vs 111 molecules/pg) of the molecules determined by means of SPT3.1 that is located in exons 1 and 2 [16]. In clear contrast to what occurs in Sptrx-1 and Sptrx-3 mRNA quantification, SPT2.1 that amplifies most of the sequence encoding the Nterminal thioredoxin domain of Sptrx-2, yielded the same number of mRNA molecules as SPT2.2 (294 vs 273 molecules/pg), which amplifies part of the sequence encoding its first complete NDP-kinase domain.

With respect to the temporal expression pattern of the Sptrx mRNAs (Table 3), outstanding findings are as follows: (i) While the Sptrx-1 transcripts were at appreciable levels in testes from animals of all examined ages [from pre-pubertal (1/2-week-old) to adult (4- to 7-week-old) mice], Sptrx-2 and Sptrx-3 mRNAs were basically restricted to the post-pubertal testis. (ii) Nonetheless, the Sptrx-1 mRNA was infrequently expressed in pre-pubertal testis, standing for < $0.3 \%$ of the adult amounts. (iii) Adult testes of different ages displayed significant different levels of Sptrx-1, Sptrx-2 and Sptrx-3 mRNAs (data from SPT1.2, SPT2.1 and SPT3.1 primer pairs, respectively); the amounts of mRNA in $4 / 5$-week-old testes accounted for about $50 \%$ of the mRNA molecules quantified in 7-week-old testes. (iv) Primer-associated differences in Sptrx-1 and Sptrx-3 mRNA levels increased as the animals aged. For instance, SPT1.5 
quantified most of the Sptrx-1 mRNA molecules given by SPT1.2 in pre-pubertal testes, whereas in adult mice, 4/5 and 7-weeks of age, SPT1.5 quantified only $18 \%$ and $9.4 \%$, respectively, of the molecules determined by means of SPT1.2.

Conversely to the age-associated differences in testicular Sptrx mRNA levels, Trx1 and TrxR1 transcript amounts remained basically unchanged as the animals aged. Interestingly, however, $T G R$ mRNA abundance was reduced in young animals, particularly in pre-pubertal 1/2-week-old mice, similar to the situation with Sptrx mRNAs. Although Trx1, TrxR1 and TGR transcripts are all present in testis, only TGR mRNA is highly overproduced in this organ as compared to other mouse tissues [25].

\subsection{Primer-Associated Differences in Testicular mRNA Levels}

The unforeseen differences found in association with the primer pair used for quantification of Sptrx-1 and Sptrx-3 mRNAs (Table 3), were further investigated by designing additional primer pairs (Table 2). For comparison, a new SPT2.3 primer pair was also designed for quantification of Sptrx-2 mRNA molecules. To shorten the analysis, quantifications were made in a unique sample of testicular RNA pooled from 9 out of the 12 mice of 7 weeks of age.

As shown in Table 4, the highest number of Sptrx-1 mRNA molecules (1226 molecules/pg) was determined by means of SPT1.2. Primer pairs located either up- or down-stream of SPT1.2 quantified only part of the Sptrx-1 transcripts. Thus, SPT1.1 detected $66 \%$ (814 molecules/pg) of the maximal Sptrx-1 mRNA molecules given by SPT1.2. This finding indicates that, while methionine 4, chosen as the start site [13], is encoded by all Sptrx-1 transcripts, $44 \%$ of them lack codons for the alternative potential starts methionine 2 and 3. With respect to those primer pairs (SPT1.3 to SPT1.7) located downstream of SPT1.2, an outstanding progressive reduction was detected in Sptrx-1 mRNA abundance, running in the 5' - to 3' direction. This finding indicates that $<10 \%$ of all Sptrx-1 transcripts quantified by means of SPT1.2, contain the sequence encoding the C-terminal thioredoxin domain, where SPT1.5 to SPT1.7 are located (see Table 2). Such a striking accumulation of truncated Sptrx-1 transcripts is consistent with premature transcription termination and/or transcript degradation, and it may be related to the extremely short 3'-UTR exhibited by both mouse and human Sptrx-1 mRNAs [12, 13].

With regard to Sptrx-3 mRNA, data in Table 4 indicate that whereas exons 1 to 4 are present in all transcript molecules (SPT3.1, SPT3.2 and SPT3.3 data), exon 5 (SPT3.4) or exon 6 (SPT3.5) are present in a rather small percentage (12\% each) of total molecules. In agreement 
with data in Table 3, exons 5 and 6 (SPT3.6) were simultaneously present only in $4 \%$ of Sptrx-3 mRNAs.

In contrast to the above referred findings on Sptrx-1 and Sptrx-3 mRNAs, similar number of transcript copies (at about 270 molecules/pg) was determined by the three (SPT2.1, SPT2.2 and SPT2.3) primer pairs designed for quantification of Sptrx-2 mRNA.

\subsection{Tissue Distribution of Sptrx mRNA}

As previously mentioned, initial multiple-tissue northern blots identified adult testis as the only organ expressing Sptrx-1, Sptrx-2 and Sptrx-3 mRNAs [6], with no hybridization signal being obtained in any other tissue despite the use of low stringency conditions and extended exposure time. Given the sensitivity and reproducibility of real-time PCR for absolute quantification of Sptrx mRNA levels in vivo (Table 3), we further quantified the actual copy numbers of Sprtx-1, Sprtx-2 and Sprtx-3 mRNAs in a variety of adult (7-week-old) tissues other than testis. Total Sptrx-2 and Sptrx-3 mRNAs were quantified by means of SPT2.1 and SPT3.1 pair primers, respectively. With regard to Sptrx-1, maximal transcript amounts were quantified by means of SPT1.2, and the specific percentage retaining the sequence for the C-terminal thioredoxin domain by SPT1.5. We confirmed the testis-specific expression pattern of Sptrx-2 and Sptrx-3 genes, since their transcripts were nearly absent $(\leq 0.001$ molecules/pg) in lung, heart, brain, liver, kidney, spleen and ovary. However, in contrast to previous findings, Sptxr-1 transcripts were present not only in testis (876 molecules/pg in Table 3) but also in lung, heart and brain (although at very low levels of about 0.07 molecules/pg), and to a higher extent in ovary (6.3 molecules/pg). Interestingly, when only considering those Sptrx-1 transcripts containing the sequence for the C-terminal domain, the ovary level (3.3 molecules/pg) constituted $4 \%$ of the amount quantified in testis (82 molecules/pg in Table 3$)$. In agreement with this wider expression pattern of Sptrx-1, examination of EST sequences revealed its presence in cDNA from unfertilized egg and embryo, corresponding approximately to $11 \%$ of all available mouse Sptrx-1 EST. In contrast, Sptrx-2 and Sptrx-3 sequences were detected in EST exclusively from testes. 


\section{DISCUSSION}

Regulation of gene expression during spermatogenesis is exerted according to a complex and coordinated scheme where different cis-acting and trans-acting elements converge to either activate, modify or silence the expression of a particular group of specific genes responsible for the formation of a specialized cell as the spermatozoon. Among those gene products participating in the spermatogenic process we have recently identified three sperm-specific thioredoxins [6]. Since control of redox imbalance has been reported to be important in both the physiology of normal spermatogenesis and the aetiology of some spermatogenic abnormalities [26], regulation of Sptrx gene expression is likely to be of great importance.

Sptrx proteins are expressed either in different structures within the sperm cell or at different stages of sperm development [6] and, therefore, the regulation of their specific expression pattern should differ for each Sptrx gene. We first investigated the transcription initiation of the Sptrx genes by promoter analysis of their respective 5'-flanking regions, ranging from $-1 \mathrm{~kb}$ to $4 \mathrm{~kb}$, because distal regulatory regions are frequently responsible of cell type-specific expression $[27,28]$. Experiments were carried out in the mouse spermatogenic GC-2spd(ts) cell line, where a recent study has identified the regulatory factor X2 to activate transcription of the testisspecific histone Ht1 gene [29]. Although, neither Sptrx proteins nor mRNAs are found in GC2 spd(ts) cells we completed the promoter analysis as a first approach to establish which fragments in the 5 '-flanking regions are responsible for the transcriptional silencing of Sptrx genes in GC-2spd(ts) cells and somatic cell lines.

In silico analyses and luciferase assays indicate that the putative promoters for all Sptrx genes must be contained in the $-1.5 \mathrm{~kb}$ proximal region from their respective ATG codons, where different regulatory elements are predicted to be located. However, the Sptrx-1 $-1 \mathrm{~kb}$ region, lacking any TATA-box, does not show promoter activity. One could speculate that the EGRF/NFAT module (located at -1091 to -1113 ) is essential for the activity because the Sptrx$1-2 \mathrm{~kb}$ region, which contains this module, indeed exhibits the highest activity. Besides, the $-1-$ $2 \mathrm{~kb}$ region, apart from harbouring three predicted TATA-boxes at $-1163,-1294$ and -1752 , contains several transcription binding-sites (data not shown), which may be functional to activate Sptrx-1 transcription. Also, the presence of a 525 bp intron within the 5'-UTR of Sptrx1 [13] suggests that the transcription initiation site, and therefore other cis-regulating sequences necessary for transcriptional initiation of Sptrx-1, should be located upstream of this intron ($639 \mathrm{bp}$ from the ATG codon). 
Importantly, the Sptrx-1 and Sptrx-2 -2kb distal regions may function as transcriptional silencers since $-4 \mathrm{~kb}$ constructs lack any promoter activity being even lower than pGL-3 basic empty vector basal activity. Since it is known that methylation status of $\mathrm{CpG}$ dinucleotides in CpG-poor promoters is important for transcriptional silencing [30-32], we made a prediction for $\mathrm{CpG}$ islands in the Sptrx 5'-flanking regions using the $C p G$ island finder from EMBOSS tools (http://www.ebi.ac.uk/emboss/). One CpG island in the Sptrx-1 and three in the Sptrx-2 (but none in Sptrx-3) -2kb distal regions were found, suggesting that the status of these predicted CpG islands might play a role on the somatic transcriptional silencing of Sptrx-1 and Sptrx-2 genes.

The Sptrx-3 transcriptional repression seems to be regulated in a completely different way than that of Sptrx-1 and Sptrx-2. The fact that neither Sptrx-3 mRNA nor protein are found in GC-2spd(ts) cells while Sptrx-3 constructs (except the $-3 \mathrm{~kb}$ construct) exhibit promoter activity, raises an apparent contradiction. One explanation can be a silencing sequence located in the 3'flanking region as occurs in other genes such as the murine CD46 [33]; however, additional experiments are required to support such a notion. On the other hand, the Sptrx-3 1kb distal region $(-3-4 \mathrm{~kb}$ from ATG) is likely to contain an upstream activating sequence from where spermatogenic-specific factors may enhance Sptrx-3 transcription. In fact, the Sptrx-3 1kb distal region alone does not show any promoter activity (data not shown) and therefore is not able to direct Sptrx-3 transcription by itself. Nonetheless, our results indicate that the presence of this region in $-4 \mathrm{~kb}$ Sptrx-3 constructs can increase the promoter activity in GC-2spd(ts) cells, but not in Y-1 or Hepa1-6 cells.

Apart of transcription initiation regulation, we have also investigated how the steady-state Sptrx mRNA amounts change during mouse development and whether post-transcriptional mechanisms can affect Sptrx gene expression. We performed real-time PCR in whole-animal experiments, which revealed interesting new features about Sptrx transcription patterns. Sptrx-1 mRNA is detected in testes from pre-pubertal animals (1-2 weeks) although at very low levels. In contrast, Sptrx-2 and Sptrx-3 mRNA are first identified after puberty (4-5 weeks and onwards) as described before $[15,16]$. In addition, Sptrx-1, Sptrx-2 and Sptrx-3 mRNA levels in adult testes are significantly different and increase when animals age.

We also found vast primer-associated differences for expression of Sptrx-1 and Sptrx-3, which increased with age as well. Several mechanisms have been described to operate during spermatogenesis such as different transcription start site usage, mRNA degradation and alternative splicing [21] and it is possible that some of these mechanisms may explain these disparities. 
For Sptrx-1, differences in results with SPT1.1 and SPT1.2 primer pairs may be explained by the existence of several transcription start sites upstream and downstream the SPT1.1 annealing sequence. As SPT1.1 amplifies about $2 / 3$ of the total transcripts that SPT1.2 does, major transcription start site/s should be located downstream of the SPT1.1 annealing sequence. On the other hand, a main feature of the Sptrx-1 gene is the presence of only one intron in the $5^{\prime}$-UTR region, between potential start methionine 3 and 4 . Regulatory sequences within this intron might also explain the lower amount of Sprtx-1 transcript molecules quantified by SPT1.1 as compared to SPT1.2. Conversely, differences between SPT1.2 and SPT1.3 compared to SPT1.7 may be related to mRNA degradation or shortening at the 3'-end, a mechanism that has been proposed to play a key role in the control of gene expression [34]. This degradation mechanism may be associated to the particularly short 3'-UTR of 17bp of mouse Sptrx-1 [17]. Interestingly, we found that only $<10 \%$ of all Sptrx-1 transcripts retain the C-terminal thioredoxin domain and thereby their functionality.

With regard to the Sptrx-3 primer-associated differences, we hypothesize that two major mechanisms may operate in this case: mRNA degradation at the 3 '-end and alternative splicing within Sptrx-3 exon 5. Although $45-S p t r x-3$ splicing variant has not been identified in humans [16], we cloned this splicing variant from a mouse testis cDNA library (Clontech). Thus, the primer pair SPT3.4 can detect full-length transcripts and also partially degraded mRNAs, whereas SPT3.5 amplifies full-length transcripts and $\Delta 5-$ Sptrx-3 spliced variants and SPT3.6 detecting all the full-length non-degraded Sptrx-3 mRNAs. Taken together, and considering as functional only those mRNAs amplified by the SPT3.5 pair (full-length and $\Delta 5-$ Sptrx-3), it seems that on an average of about 125 Sptrx-3 transcripts per pg of total RNA, no more than $11.9 \%$ are functional, corresponding $8.2 \%$ to the more abundant $\Delta 5$-Sptrx-3 transcripts and only $3.7 \%$ to full-length transcripts.

In conclusion, these results indicate that transcription of Sptrx genes is exquisitely regulated and that the developing spermatozoon needs to fine-tune the expression of these genes to complete its development. This work constitutes an initial analysis of Sptrx genes transcription regulation and additional experiments in a more physiological context such as promoter analyses by in vivo electroporation [35] are envisaged to complement the present work. 


\section{ACKNOWLEDGEMENTS}

This work was supported by the Swedish Medical Research Council (projects 03P-14096, 03X14041, and 13X-10370), the Åke Wibergs Stiftelse, the Karolinska Institutet and the Spanish Ministerio de Ciencia y Tecnología (grant BMC2002-00179). A. Jiménez was supported by a postdoctoral fellowship (EX2003-0390) from the Spanish Ministerio de Educación, Cultura y Deporte. M-J. Prieto-Álamo and J. Jurado were recipients of postdoctoral contracts (Programa Ramón y Cajal) from the Spanish Ministerio de Ciencia y Tecnología. 


\section{REFERENCES}

[1] J. Nordberg, and E. S. Arner, Reactive oxygen species, antioxidants, and the mammalian thioredoxin system, Free Radic Biol Med 31 (2001) 1287-1312.

[2] S. Gromer, S. Urig, and K. Becker, The thioredoxin system-From science to clinic, Med Res Rev 24 (2004) 40-89.

[3] K. Hirota, H. Nakamura, H. Masutani, and J. Yodoi, Thioredoxin superfamily and thioredoxin-inducing agents, Ann N Y Acad Sci 957 (2002) 189-199.

[4] A. Holmgren, Antioxidant function of thioredoxin and glutaredoxin systems, Antioxid Redox Signal 2 (2000) 811-820.

[5] A. Miranda-Vizuete, A. E. Damdimopoulos, and G. Spyrou, The mitochondrial thioredoxin system, Antioxid Redox Signal 2 (2000) 801-810.

[6] A. Miranda-Vizuete, C. M. Sadek, A. Jimenez, W. J. Krause, P. Sutovsky, and R. Oko, The Mammalian testis-specific thioredoxin system, Antioxid Redox Signal 6 (2004) 25-40.

[7] P. M. Cunnea, A. Miranda-Vizuete, G. Bertoli, T. Simmen, A. E. Damdimopoulos, S. Hermann, S. Leinonen, M. P. Huikko, J.-Å. Gustafsson, R. Sitia, and G. Spyrou, ERdj5, an endoplasmic reticulum (ER)-resident protein containing DnaJ and thioredoxin domains, is expressed in secretory cells or following ER stress, J Biol Chem 278 (2003) 1059-1066.

[8] A. Hosoda, Y. Kimata, A. Tsuru, and K. Kohno, JPDI, a novel endoplasmic reticulumresident protein containing both a BiP-interacting J-domain and thioredoxin-like motifs, $\mathrm{J}$ Biol Chem 278 (2003) 2669-2676.

[9] Q. A. Sun, L. Kirnarsky, S. Sherman, and V. N. Gladyshev, Selenoprotein oxidoreductase with specificity for thioredoxin and glutathione systems, Proc Natl Acad Sci U S A 98 (2001) 3673-3678.

[10] A. K. Rundlöf, M. Jarnard, A. Miranda-Vizuete, and E. S. Arnér, Evidence for intriguingly complex transcription of human thioredoxin reductase 1, Free Radic Biol Med 36 (2004) 641-656.

[11] A. K. Rundlöf, and E. S. Arnér, Regulation of the Mammalian Selenoprotein Thioredoxin Reductase 1 in Relation to Cellular Phenotype, Growth, and Signaling Events, Antioxid Redox Signal 6 (2004) 41-52.

[12] A. Miranda-Vizuete, J. Ljung, A. E. Damdimopoulos, J.-Å. Gustafsson, R. Oko, M. PeltoHuikko, and G. Spyrou, Characterization of Sptrx, a novel member of the thioredoxin family specifically expressed in human spermatozoa, J Biol Chem 276 (2001) 3156731574.

[13] A. Jiménez, R. Oko, J.-Å. Gustafsson, G. Spyrou, M. Pelto-Huikko, and A. MirandaVizuete, Cloning, expression and characterization of mouse spermatid specific thioredoxin1 gene and protein, Mol Hum Reprod 8 (2002) 710-718.

[14] C. M. Sadek, A. E. Damdimopoulos, M. Pelto-Huikko, J.-Å. Gustafsson, G. Spyrou, and A. Miranda-Vizuete, Sptrx-2, a fusion protein composed of one thioredoxin and three tandemly repeated NDP-kinase domains is expressed in human testis germ cells, Genes Cells 6 (2001) 1077-1090.

[15] A. Miranda-Vizuete, K. Tsang, Y. Yu, A. Jiménez, M. Pelto-Huikko, C. J. Flickinger, P. Sutovsky, and R. Oko, Cloning and Developmental Analysis of Murid Spermatid-specific Thioredoxin-2 (SPTRX-2), a Novel Sperm Fibrous Sheath Protein and Autoantigen, J Biol Chem 278 (2003) 44874-44885.

[16] A. Jiménez, W. Zu, V. Y. Rawe, M. Pelto-Huikko, C. J. Flickinger, P. Sutovsky, J.-Å. Gustafsson, R. Oko, and A. Miranda-Vizuete, Spermatocyte/spermatid-specific thioredoxin-3, a novel Golgi apparatus-associated thioredoxin, is a specific marker of aberrant spermatogenesis, J Biol Chem 279 (2004) 34971-34982. 
[17] A. Jiménez, C. Johansson, J. Ljung, J. Sagemark, K. D. Berndt, B. Ren, G. Tibbelin, R. Ladenstein, T. Kieselbach, A. Holmgren, J. A. Gustafsson, and A. Miranda-Vizuete, Human spermatid-specific thioredoxin-1 (Sptrx-1) is a two-domain protein with oxidizing activity, FEBS Lett 530 (2002) 79.

[18] K. Willison and A. Ashworth, Mammalian spermatogenic gene expression, Trends Genet 3 (1987) 351-355.

[19] R. P. Erickson, Post-meiotic gene expression, Trends Genet 6 (1990) 264-269.

[20] A. Hochheimer, and R. Tjian, Diversified transcription initiation complexes expand promoter selectivity and tissue-specific gene expression, Genes Dev 17 (2003) 1309-1320.

[21] K. C. Kleene, A possible meiotic function of the peculiar patterns of gene expression in mammalian spermatogenic cells, Mech Dev 106 (2001) 3-23.

[22] D. Elliott, Pathways of post-transcriptional gene regulation in mammalian germ cell development, Cytogenet Genome Res 103 (2003) 210-216.

[23] M. J. Prieto-Alamo, J. M. Cabrera-Luque, and C. Pueyo, Absolute quantitation of normal and ROS-induced patterns of gene expression: an in vivo real-time PCR study in mice, Gene Expr 11 (2003) 23-34.

[24] M. C. Hofmann, R. A. Hess, E. Goldberg, and J. L. Millan, Immortalized germ cells undergo meiosis in vitro, Proc Natl Acad Sci U S A 91 (1994) 5533-5537.

[25] J. Jurado, M. J. Prieto-Alamo, J. Madrid-Risquez, and C. Pueyo, Absolute gene expression patterns of thioredoxin and glutaredoxin redox systems in mouse, J Biol Chem 278 (2003) 45546-45554.

[26] R. J. Aitken, A. L. Ryan, B. J. Curry, and M. A. Baker, Multiple forms of redox activity in populations of human spermatozoa, Mol Hum Reprod 9 (2003) 645-661.

[27] M. A. Yui, G. Hernandez-Hoyos, and E. V. Rothenberg, A new regulatory region of the IL2 locus that confers position-independent transgene expression, J Immunol 166 (2001) 1730-1739.

[28] G. Lakshmanan, K. H. Lieuw, K. C. Lim, Y. Gu, F. Grosveld, J. D. Engel, and A. Karis, Localization of distant urogenital system-, central nervous system-, and endocardiumspecific transcriptional regulatory elements in the GATA-3 locus, Mol Cell Biol 19 (1999) $1558-1568$.

[29] S. A. Wolfe, D. C. Wilkerson, S. Prado, and S. R. Grimes, Regulatory factor X2 (RFX2) binds to the H1t/TE1 promoter element and activates transcription of the testis-specific histone H1t gene, J Cell Biochem 91 (2004) 375-383.

[30] S. Eden, and H. Cedar, Role of DNA methylation in the regulation of transcription, Curr Opin Genet Dev 4 (1994) 255-259.

[31] C. De Smet, A. Loriot, and T. Boon, Promoter-dependent mechanism leading to selective hypomethylation within the 5' region of gene MAGE-A1 in tumor cells, Mol Cell Biol 24 (2004) 4781-4790.

[32] Z. Siegfried, S. Eden, M. Mendelsohn, X. Feng, B. Z. Tsuberi, and H. Cedar, DNA methylation represses transcription in vivo, Nat Genet 22 (1999) 203-206.

[33] M. Nomura, A. Tsujimura, N. A. Begum, M. Matsumoto, H. Wabiko, K. Toyoshima, and T. Seya, Identification and characterization of a silencer regulatory element in the 3'flanking region of the murine CD46 gene, Biochem J 351 Pt 2 (2000) 353-365.

[34] R. Parker, and H. Song, The enzymes and control of eukaryotic mRNA turnover, Nat Struct Mol Biol 11 (2004) 121-127.

[35] P. Bigey, M. F. Bureau, and D. Scherman, In vivo plasmid DNA electrotransfer, Curr Opin Biotechnol 13 (2002) 443-447. 
FIGURE LEGENDS

Fig. 1. Diagram of the constructs used in the luciferase assays. 5'-flanking regions from ATG of Sptrx genes were inserted upstream of a firefly luciferase reporter gene. RO, reverse orientation; U, upstream.

Fig. 2. Promoter activity of Sptrx 5'-flanking regions in GC-2spd(ts) cells. Different 5'flanking region constructs (Fig. 1) of Sptrx-1, Sptrx-2 and Sptrx-3 were used in a luciferase reporter gene assay in GC-2spd(ts) cells. " $n$. $t$.", non transfected. Bars indicate mean $\pm \mathrm{SEM}$ with data expressed as percentage of promoter activity compared to that of the pGL-3 empty vector. Comparisons among constructs were performed using ANOVA followed by the StudentNewman-Keuls post-hoc test $(\mathrm{N}=3-6, \mathrm{P}<0.05)$. Statistical significant differences with respect to pGL-3 empty vector are indicated with an asterisk.

Fig. 3. Schematic representation of Sptrx 5'-flanking regions. Predicted promoter sequences, regulatory modules and repetitive sequences are drawn for each Sptrx gene according to the output forms from GenomatixSuite 3.1.1 software (http://www.genomatix.de/).

\section{Supplemental Data Fig 1. Promoter activity of Sptrx 5'-flanking regions in GC-2spd(ts),} Hepa1-6 and Y-1 cell lines. Different constructs of Sptrxs 5'-flanking regions (Fig. 1) were used in a luciferase reporter gene assay in Hepa1-6 (white bars), Y-1 (grey bars) and GC2 spd(ts) (black bars) cells. " $n$. $t$.", non transfected. Bars indicate mean \pm SEM with data expressed as percentage of promoter activity compared to that of the pGL-3 empty vector. Comparisons among constructs were performed using ANOVA followed by the StudentNewman-Keuls post-hoc test $(\mathrm{N}=3-6, \mathrm{P}<0.05)$. Statistical significant differences with respect to pGL-3 empty vector are indicated with an asterisk. No significant differences are indicated as “n. s." 
Table 1. Putative transcription binding sites in $-1 \mathrm{~kb}$ 5'-flanking regions of Sptrx genes

\begin{tabular}{|c|c|c|}
\hline $\begin{array}{l}\text { 5'-flanking } \\
\text { region }\end{array}$ & $\begin{array}{c}\text { Transcription } \\
\text { binding site }\end{array}$ & $\begin{array}{l}\text { nt position } \\
\text { from } A T G\end{array}$ \\
\hline \multirow[t]{9}{*}{ Sptrx-1 } & AP-4 & -840 \\
\hline & GC-box & -611 \\
\hline & Basic Krueppel-like factor & -613 \\
\hline & AREB-6 & -383 \\
\hline & c-Myc/Max & -349 \\
\hline & v-Myb & -323 \\
\hline & MEF-2 & -226 \\
\hline & MSX-1 and MSX-2 & $-145,-137$ \\
\hline & Retinoic acid receptor & -23 \\
\hline \multirow[t]{9}{*}{ Sptrx-2 } & GC-box & -962 \\
\hline & MAZ binding site & $-960,-758$ \\
\hline & TATA-box & -518 \\
\hline & Octamer binding factor & -487 \\
\hline & Nuclear factor Y & -312 \\
\hline & Binding site for $\mathrm{S} 8$ type homeodomains & -309 \\
\hline & HOX-1.3 & -274 \\
\hline & CCAAT/enhancer binding protein & -195 \\
\hline & Activating transcription factor & -161 \\
\hline \multirow[t]{15}{*}{ Sptrx-3 } & SP-1 like transcription factor TIEG & -991 \\
\hline & $\mathrm{BRN}-2$ & $\begin{array}{l}-971,-935 \\
-931,-809\end{array}$ \\
\hline & MEF-2 & $-957,-945$ \\
\hline & TATA-box & $\begin{array}{l}-805,-563, \\
-184\end{array}$ \\
\hline & Prostate-specific homeodomain protein NKX3.1 & -799 \\
\hline & TG-interacting factor & -756 \\
\hline & GATA-3 & $\begin{array}{l}-755,-616, \\
-376\end{array}$ \\
\hline & GATA-1 & $-592,-270$ \\
\hline & NFAT & -581 \\
\hline & BTE binding protein & -515 \\
\hline & NF-kappa $\beta$ & -513 \\
\hline & CCAAT/enhancer binding protein & -479 \\
\hline & Binding site for $\mathrm{S} 8$ type homeodomains & -435 \\
\hline & Nuclear factor $Y$ & -128 \\
\hline & CCAAT-box & -128 \\
\hline
\end{tabular}


Table 2. Primers used for quantification of mRNA molecules

\begin{tabular}{|c|c|c|c|c|c|}
\hline \multirow{2}{*}{$\begin{array}{c}\text { Target } \\
\text { (GenBank) }\end{array}$} & \multicolumn{4}{|c|}{ Primers } & \multirow{2}{*}{$\begin{array}{l}\text { Fragment } \\
\text { size }(b p)^{c}\end{array}$} \\
\hline & $\begin{array}{l}\text { Primer } \\
\text { pair name }\end{array}$ & Sequence $^{\mathrm{a}}$ & 5'-position & Exon $^{b}$ & \\
\hline Sptrx-1 & SPT1.1 & $\begin{array}{l}\text { 5'-AAAGAATAAGGACAAGGGGCTGGACATGAAC-3' (F) } \\
\text { 5'-CTTTCATTTGCTTTTCCTCCGTTGTTGAGTG-3' (R) }\end{array}$ & $\begin{array}{c}93 \\
191\end{array}$ & $\begin{array}{l}1 \\
1\end{array}$ & 99 \\
\hline \multirow[t]{6}{*}{ (AF196282) } & SPT1.2 & $\begin{array}{l}\text { 5'-TGAAAGGGGCAGCAACGAAAATCCATTAC-3' (F) } \\
\text { 5'-GGACGGTATTCTCTGAAAACATGGGGGTG-3' (R) }\end{array}$ & $\begin{array}{l}186 \\
385\end{array}$ & $\begin{array}{c}1-2 \\
2\end{array}$ & 200 \\
\hline & SPT1.3 & 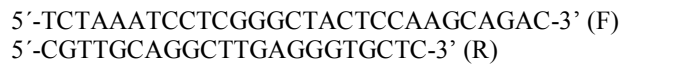 & $\begin{array}{l}451 \\
555\end{array}$ & $\begin{array}{l}2 \\
2\end{array}$ & 105 \\
\hline & SPT1.4 & $\begin{array}{l}\text { 5'-GACAGCGTTCAGTCAAAGGAGAGTGAAGA-3' (F) } \\
\text { 5'-TTCCTGGGACTGGATGGTGTCTTCTTC-3' (R) }\end{array}$ & $\begin{array}{l}1096 \\
1293\end{array}$ & $\begin{array}{l}2 \\
2\end{array}$ & 198 \\
\hline & SPT1.5 & $\begin{array}{l}\text { 5'-TTGGAGCAGAAATAGAGACCCTGGAGGAAG-3' (F) } \\
\text { 5'-CCACCAGCTTCTCTCCAGCGTCTTTG-3' (R) }\end{array}$ & $\begin{array}{l}1355 \\
1456\end{array}$ & $\begin{array}{l}2 \\
2\end{array}$ & 102 \\
\hline & SPT1.6 & $\begin{array}{l}\text { 5'-TTGGAGCAGAAATAGAGACCCTGGAGGAAG-3' (F) } \\
\text { 5'-GGGAGGTGAAAGATCTCACAGTCTTGCAC-3' (R) }\end{array}$ & $\begin{array}{l}1355 \\
1610\end{array}$ & $\begin{array}{l}2 \\
2\end{array}$ & 256 \\
\hline & SPT1.7 & $\begin{array}{l}\text { 5'-TTTGAAGCACGAGGATGTGATATTCTTGGAG-3' (F) } \\
\text { 5'-ACAAGGGCACCAGAAAATTCACCCAC-3' (R) }\end{array}$ & $\begin{array}{l}1524 \\
1667\end{array}$ & $\begin{array}{l}2 \\
2\end{array}$ & 144 \\
\hline Sptrx-2 & SPT2.1 & $\begin{array}{l}\text { 5'-CAAAAAGCGTGAAGTCCAGCTACAGTCAGTC-3' (F) } \\
\text { 5'-TTCAGCAACGACGAAGTGAAGAATCTCATC-3' (R) }\end{array}$ & $\begin{array}{l}150 \\
345\end{array}$ & $\begin{array}{l}2-3 \\
4-5\end{array}$ & 196 \\
\hline \multirow[t]{2}{*}{ (AF548543) } & SPT2.2 & $\begin{array}{l}\text { 5'-GTGAGGAAGAGAAAGATGACGTGTTGAACG-3' (F) } \\
\text { 5'-ATGGATCTTGCACACTGTTCTTGCTTCTTC-3' (R) }\end{array}$ & $\begin{array}{l}1112 \\
1227\end{array}$ & $\begin{array}{c}11-12 \\
12\end{array}$ & 116 \\
\hline & SPT2.3 & $\begin{array}{l}\text { 5'-AGCCTC ATGTGACACACAAAGAAAGAATGG-3' (F) } \\
\text { 5'-ACCATGACTAGCGACATGCCCAAAGATAAG-3' (R) }\end{array}$ & $\begin{array}{l}1505 \\
1697\end{array}$ & $\begin{array}{l}14-15 \\
15-16\end{array}$ & 193 \\
\hline Sptrx-3 & SPT3.1 & $\begin{array}{l}\text { 5'-CAGCAGCAAGTCCCAGATGTTAATCATGGT-3' (F) } \\
\text { 5' }^{\prime} \text {-TTGTTTCCAGCATCGCTGAACAATTCTTTC-3' (R) }\end{array}$ & $\begin{array}{c}49 \\
135\end{array}$ & $\frac{1}{2}$ & 87 \\
\hline \multirow[t]{5}{*}{ (AY495589) } & SPT3.2 & $\begin{array}{l}\text { 5'-TGAAAGAATTGTTCAGCGATGCTGGAAAC-3' (F) } \\
\text { 5'-AGATGAGTCCACATCCACCTGAGCAAAC-3' (R) }\end{array}$ & $\begin{array}{l}105 \\
259\end{array}$ & $\begin{array}{l}2 \\
3\end{array}$ & 155 \\
\hline & SPT3.3 & $\begin{array}{l}\text { 5'-GCTTGTGGTGGTAGAGTTTTCAGCAAAGTG-3' (F) } \\
\text { 5'-ATCTGGAATGTGGGTAGCATTGTGATGTC-3' (R) }\end{array}$ & $\begin{array}{l}136 \\
309\end{array}$ & $\begin{array}{l}2 \\
4\end{array}$ & 174 \\
\hline & SPT3.4 & $\begin{array}{l}\text { 5'-AAAATGTCACGTTTGCTCAGGTGGATGTG-3' (F) } \\
\text { 5'-CTTCGGTCCACTTCTGAGGCAGCAC-3' (R) }\end{array}$ & $\begin{array}{l}222 \\
385\end{array}$ & $\begin{array}{l}3 \\
5\end{array}$ & 164 \\
\hline & SPT3.5 & $\begin{array}{l}\text { 5'-AAA ATGTCACGTTTGCTCAGGTGGATGTG-3' (F) } \\
\text { 5'-TTTCCAGTTGTTTAGCATCAGCTCCATGACA-3' (R) }\end{array}$ & $\begin{array}{l}222 \\
434\end{array}$ & $\begin{array}{l}3 \\
6\end{array}$ & $213 / 147$ \\
\hline & SPT3.6 & $\begin{array}{l}\text { 5'-GCTGCCTCAGAAGTGGACCGAAGAG-3' (F) } \\
\text { 5'-CATGCAAGACACAGAGCATTAGCTCCTG-3' (R) }\end{array}$ & $\begin{array}{l}363 \\
521\end{array}$ & $\begin{array}{l}5 \\
6\end{array}$ & 159 \\
\hline
\end{tabular}

${ }^{\mathrm{a}}$ Sequences of forward $(\mathrm{F})$ and reverse $(\mathrm{R})$ primers.

${ }^{\mathrm{b}}$ Exon numbers were according to NCBI Evidence Viewer, except those for Sptrx-3 that were according to [16].

${ }^{c}$ Each primer pair generates a single PCR fragment. The exception is SPT3.5 that generates two fragments, the shortest of 147 bp lacking exon 5. 
Table 3. Age-associated differences in testicular mRNA levels

Transcripts were quantitated in testes from $n$ mice of different ages. Primers for amplification of Sptrx-1, Sptrx-2 and Sptrx-3 are given in Table 1, and those for $T G R$, Trx 1 and TrxRl in [25]. Data are the means \pm S.E. of mRNA molecules per pg of total RNA. Comparisons among mouse groups were done using ANOVA followed by the Student-Newman-Keuls test. Comparisons between primers were done using the Student's $t$ test. Average values with the same superscript are not statistically different $(P>0.05)$.

\begin{tabular}{|c|c|c|c|}
\hline & & Age & \\
\hline $\begin{array}{c}\text { Target } \\
\text { Primer pair }\end{array}$ & $\begin{array}{c}\text { 1/2 weeks } \\
(n=6)\end{array}$ & $\begin{array}{c}4 / 5 \text { weeks } \\
(n=6)\end{array}$ & $\begin{array}{l}7 \text { weeks } \\
(n=12)\end{array}$ \\
\hline \multicolumn{4}{|l|}{ Sptrx-1 } \\
\hline SPT1.2 & $0.22 \pm 0.016^{\mathrm{a}}$ & $369 \pm 23$ & $876 \pm 38$ \\
\hline SPT1.5 & $0.19 \pm 0.016^{\mathrm{a}}$ & $65 \pm 8.7$ & $82 \pm 2.4$ \\
\hline \multicolumn{4}{|l|}{ Sptrx-2 } \\
\hline SPT2.1 & $0.005 \pm 0.001^{b}$ & $198 \pm 4.5^{\mathrm{c}}$ & $294 \pm 15^{d}$ \\
\hline SPT2.2 & $\begin{array}{c}0.007 \\
\pm 0.001^{b}\end{array}$ & $211 \pm 5.6^{\mathrm{c}}$ & $273 \pm 18^{d}$ \\
\hline \multicolumn{4}{|l|}{ Sptrx-3 } \\
\hline SPT3.1 & $\leq 0.001$ & $60 \pm 4.0$ & $111 \pm 4.2$ \\
\hline SPT3.6 & $\leq 0.001$ & $5.5 \pm 0.70^{\mathrm{e}}$ & $4.7 \pm 0.68^{\mathrm{e}}$ \\
\hline$T G R$ & $26 \pm 2.2$ & $382 \pm 26$ & $506 \pm 13$ \\
\hline Trxy & $87 \pm 1.7^{\mathrm{f}}$ & $76 \pm 13^{f}$ & $65 \pm 3.1^{f}$ \\
\hline $\operatorname{TrxR1}$ & $11 \pm 0.56$ & $28 \pm 3.4^{\mathrm{g}}$ & $26 \pm 1.8^{\mathrm{g}}$ \\
\hline
\end{tabular}


Table 4. Primer-associated differences in testicular mRNA levels

Transcripts were quantitated in a sample of total RNA pooled from testes of 9 out of the 12 mice of 7 weeks of age analyzed individually in Table 3. Primers are given in Table 1.

\begin{tabular}{ccccc}
\hline \multicolumn{2}{c}{ Sptrx-1 } & & \multicolumn{2}{c}{ Sptrx-3 } \\
\cline { 1 - 2 } Primer pair & molecules/pg & & Primer pair & molecules/pg \\
SPT1.1 & 814 & & SPT3.1 & 114 \\
SPT1.2 & 1226 & SPT3.2 & 118 \\
SPT1.3 & 698 & SPT3.3 & 145 \\
SPT1.4 & 192 & SPT3.4 & 16 \\
SPT1.5 & 79 & & SPT3.5 & 15 \\
SPT1.6 & 61 & SPT3.6 & 4.7 \\
SPT1.7 & 48 & & \\
\hline
\end{tabular}



Supplementary Table
Click here to download Supplementary Material: 6 - Sup. Table

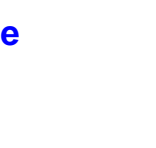

-

(

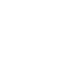

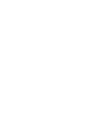

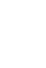

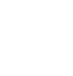

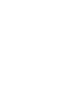

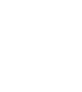

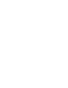

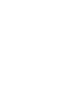

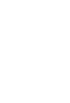

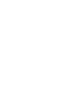

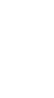

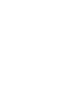
. . . t

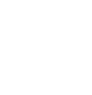

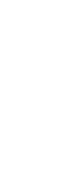

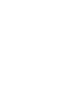

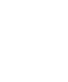

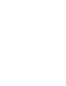

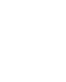

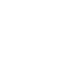

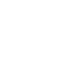

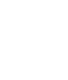

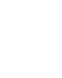

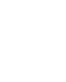

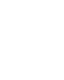

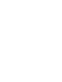

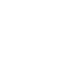

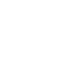

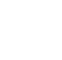




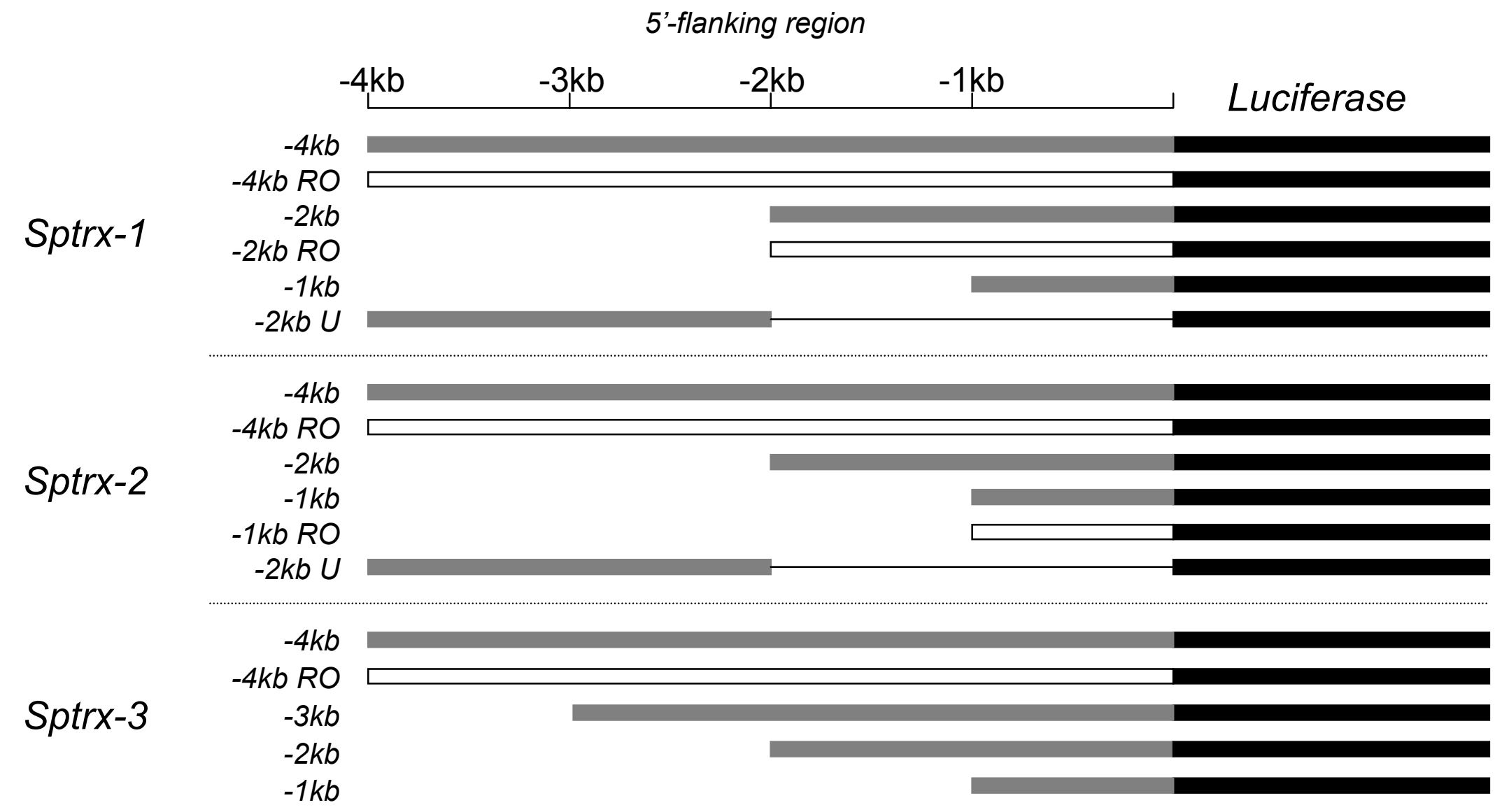

Figure 1 

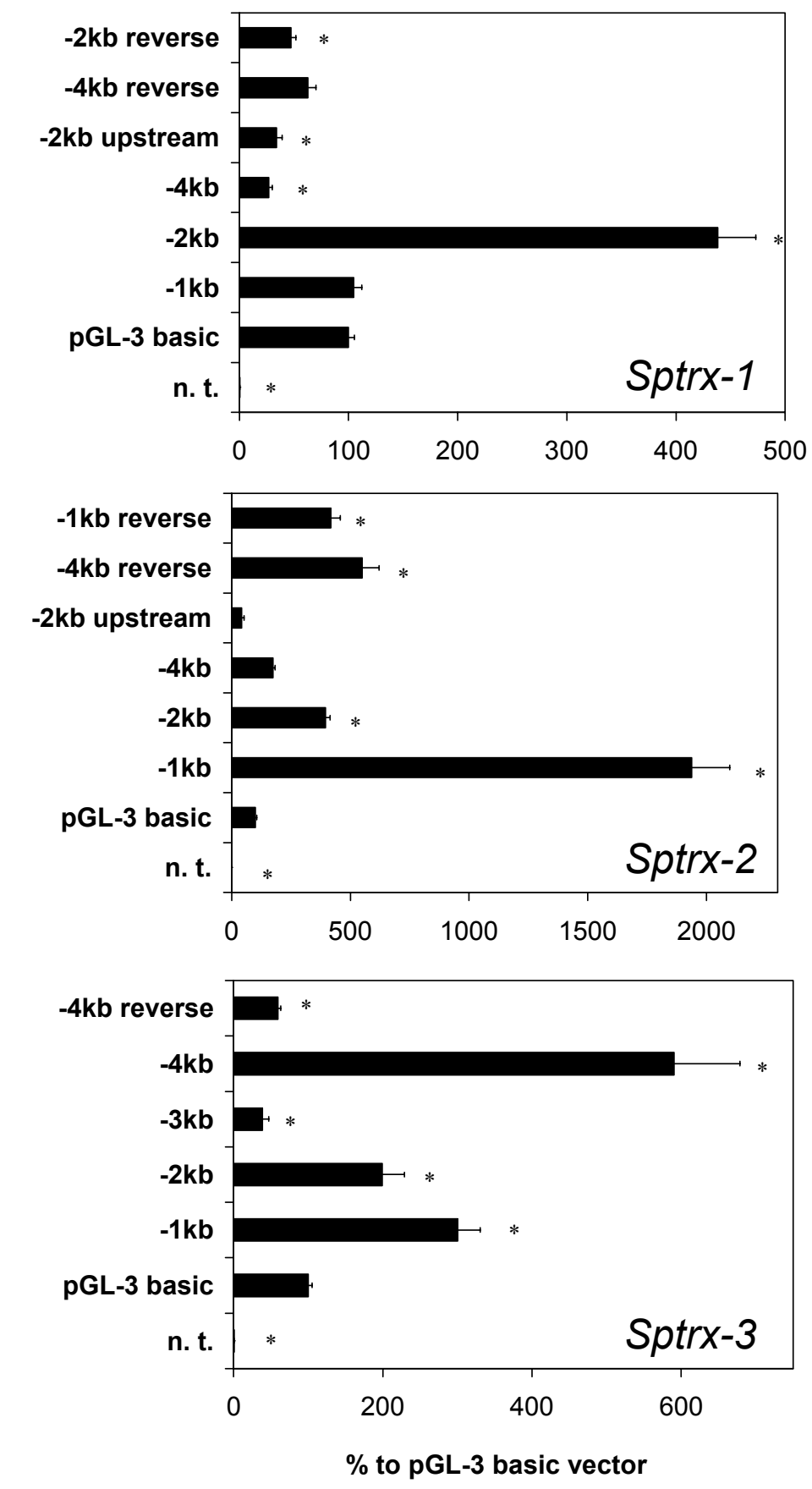

Figure 2

Figure 2 

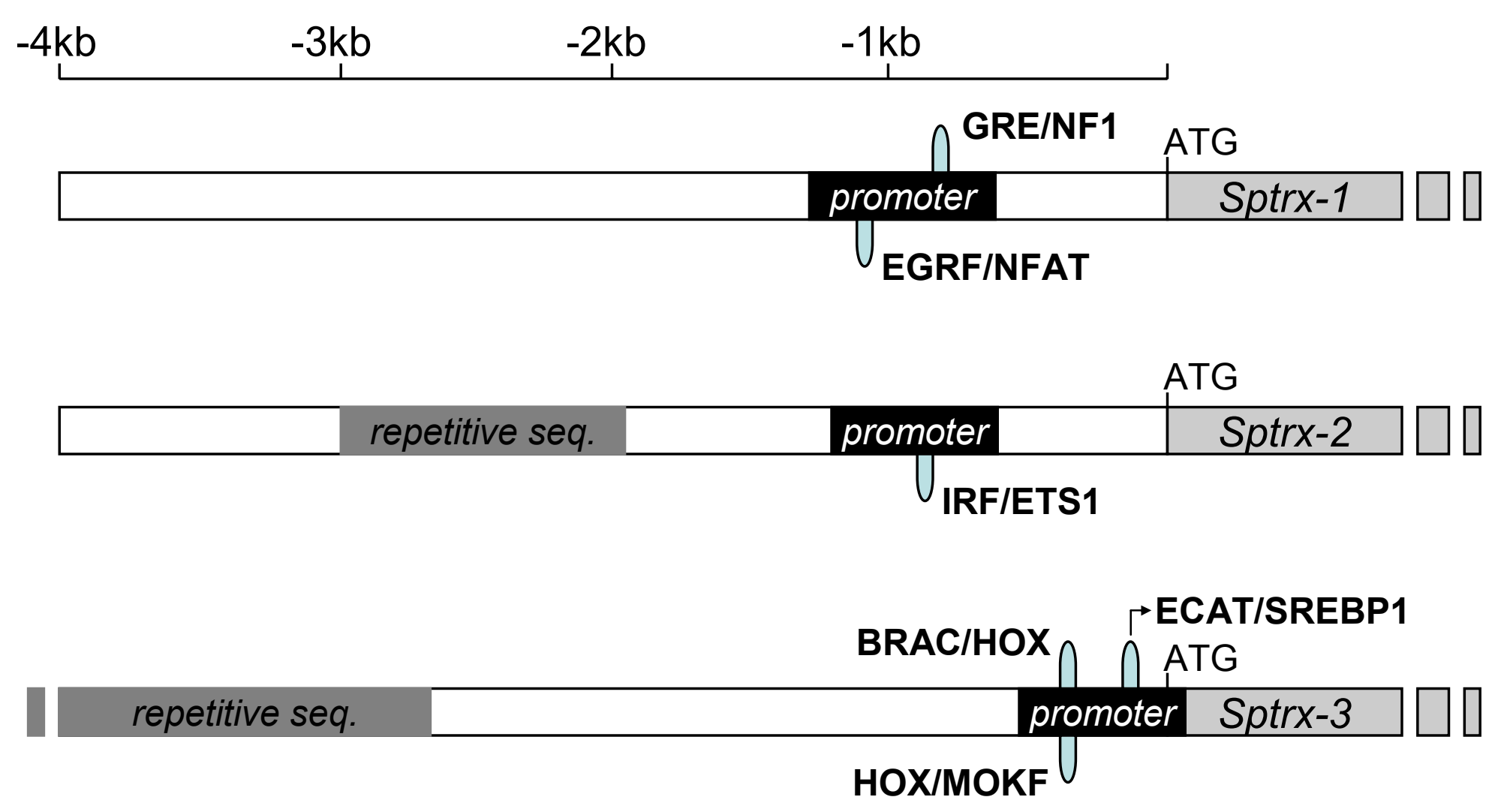

Figure 3 
Supplementary Figure
Click here to download Supplementary Material: Supplemental_Fig._1.ppt

(1) 